Revista de Economia Política, vol. 29, $n^{\circ} 3$ (115), pp. 71-92, julho-setembro/2009

\title{
Metas de inflação, política monetária e investimento: um estudo para dezessete países
}

\author{
LUIS ALBERTO PELICIONI \\ MARCO FLÁVIO DA CUNHA RESENDE*
}

Inflation targets, monetary policy and investment. In this paper two hypotheses about the relationship between monetary policy and investment in the context of the inflation target system were tested. One of these hypotheses is based on the idea of neutrality of money, and the other hypothesis is based on the reject of that idea. An investment equation for seventeen economies using a piece-wise dummy variable was estimated by the Methodology of Panel Data. The results highlight that a negative correlation between current expectation of restrictive monetary policy and current investment rose after the inflation target system implementation.

Keywords: inflation target; monetary policy; investment.

JEL Classification: E12; E13; E22;E52.

\section{INTRODUÇÃO}

O conceito de neutralidade da moeda pode ser usado como linha divisória entre heterodoxia e ortodoxia econômicas (Mollo, 2004). Na economia monetária a moeda não é neutra, quer no curto prazo, quer no longo prazo. A esfera financeira interage com a esfera real, determinando o produto, o emprego e os preços. De outro lado, para a ortodoxia econômica vale a dicotomia clássica: (pelo menos) no longo prazo a moeda não afeta as variáveis reais.

Assim, os efeitos esperados da política monetária sobre o investimento no contexto do regime de metas de inflação são distintos quando se usa o referencial

\footnotetext{
* Banco Central do Brasil, e-mail: luis.pelicioni@bcb.gov.br, e Cedeplar-UFMG e bolsista de produtividade do CNPq, e-mail: resende@cedeplar.ufmg.br. Este artigo foi aceito para o XXXV Encontro Nacional de Economia - ANPEC, Recife, 2007. Os autores agradecem a Fernando Ferrari e Frederico Gonzaga Jayme Jr. pelos comentários e sugestões a uma versão preliminar deste artigo. Submetido: Novembro de 2007; Aprovado: Fevereiro de 2008.
} 
teórico ortodoxo e o heterodoxo. $\mathrm{Na}$ abordagem pós-keynesiana, sendo a moeda não-neutra, o compromisso assumido pela autoridade monetária em fazer convergir a inflação para a meta estipulada deprime a eficiência marginal do capital e o investimento corrente através de mudanças nas expectativas dos agentes.

$\mathrm{Na}$ abordagem ortodoxa, a moeda é neutra. Assim, o combate à inflação não deve afetar o lado real da economia e a trajetória de longo prazo da acumulação de capital. Ademais, seja baseando-se em Lucas (1981), ou em Barro e Gordon (1994), não há por que esperar uma correlação negativa entre variações contemporâneas nos preços e no investimento. Lucas (1981) argumenta que há uma correlação positiva entre preços e investimento. Barro e Gordon (1994) sugerem que um governo com má reputação deve aplicar política monetária restritiva, buscando a convergência da inflação com a meta estipulada e, também, a restauração de sua credibilidade. Porém, neste caso, se houver uma correlação negativa entre inflação e investimento (supondo-se a não-neutralidade da moeda no curto prazo), esta correlação não seria entre os valores contemporâneos dessas variáveis.

Estimou-se, neste trabalho, por meio de dados em painel, uma equação para o investimento em 17 países que adotaram entre 1980 e 2005 o regime de metas de inflação. A equação de investimento contempla entre as variáveis explicativas uma proxy para expectativas de política monetária. Foi introduzida na equação de investimento uma variável dummy piece-wise para esta variável proxy. Este procedimento visou testar as hipóteses da ortodoxia e da heterodoxia econômicas, supracitadas.

O trabalho contém esta introdução e outras cinco seções. Na próxima seção os fundamentos da economia monetária são delineados. Na segunda seção debatese a relação entre política monetária e investimento em economias monetárias. $\mathrm{Na}$ terceira seção discute-se a relação entre o regime de metas de inflação, política monetária e investimento, no contexto da hipótese de neutralidade da moeda. Nas quarta e quinta seções estão os resultados da estimação da equação de investimento e as considerações finais do trabalho, respectivamente.

\section{O INVESTIMENTO EM ECONOMIAS MONETÁRIAS}

\section{Fundamentos da economia monetária}

Baseando-se em Keynes, a escola pós-keynesiana construiu um novo paradigma para a ciência econômica, em que a moeda possui papel central, não sendo neutra no curto prazo ou no longo prazo. $\mathrm{Na}$ economia monetária os axiomas neoclássicos são rompidos e novos fundamentos para a ciência econômica são introduzidos (Carvalho, 1992a, b; Davidson, 1992).

$\mathrm{Na}$ economia monetária são inerentes ao processo de produção demoras e defasagens de reação (relacionadas à disponibilidade de informação e à natureza técnica da produção). Assim, a firma produz sob expectativa de demanda, confe- 
rindo à atividade produtiva um caráter especulativo. As decisões tomadas pela firma no presente não serão necessariamente validadas no futuro. Por isso, as firmas não visam obter "utilidade", mas, sim, o máximo lucro monetário possível (Davidson, 1992, p.115; Carvalho, 1992b).

A maximização de seu lucro monetário é perseguida, visto que a moeda, por ser o ativo com a maior liquidez, confere flexibilidade ao seu detentor para aproveitar as melhores oportunidades de aumento da sua riqueza. A moeda é o ativo mais líquido porque se tornou base para contratos. Estes são essenciais para a atividade econômica, visto que as defasagens temporais presentes nos processos produtivos trazem a necessidade de coordenação (através de contratos) das relações interfirmas e intersetoriais. O papel de unidade de conta da moeda é usado para se grafar contratos e, assim, a moeda passa a exercer a função de reserva de valor ${ }^{1}$. De outro lado, as firmas são os principais agentes econômicos detentores do poder de decisão devido à "raridade" do capital. Este apresenta uma escassez relativa em função do ciclo econômico (Keynes, 1988a, p. 213).

Por fim, na economia monetária prevalece o tempo histórico, unidirecional e irreversível. Os eventos não podem se repetir de forma que os agentes desenvolvam um processo de aprendizado sobre eles. A escola pós-keynesiana argumenta que há decisões que são Cruciais. Estas decisões são aquelas que caracterizam processos irreversíveis e que alteram as condições inicialmente prevalecentes quando foram tomadas. Assim, a incerteza que emerge neste contexto de tempo histórico e Decisões Cruciais é a do tipo fundamental, não sujeita a cálculo atuarial. Então, o risco é diferente de incerteza. Aquele é quantificável, sujeito a uma distribuição de probabilidades, enquanto a incerteza não é (Amado, 2000).

Portanto, as concepções de tempo, de incerteza e de moeda são fundamentais em economias monetárias. A base para a demanda por moeda pelos motivos precaução e especulação é a incerteza ${ }^{2}$. Quando varia o "grau de confiança no estado das expectativas a longo prazo" ${ }^{3}$ dos agentes, muda a preferência por sua liquidez, afetando a demanda por moeda e a sua velocidade de circulação - e invalidando a teoria quantitativa da moeda e a Lei de Say.

Sendo um ativo alternativo aos demais, a moeda torna-se não neutra no curto e no longo prazo, pois, enquanto ativo alternativo, sua demanda pelo motivo especulação e precaução afeta a demanda por outros ativos, inclusive bens de investimento. Assim, a moeda provoca vazamentos no circuito renda-gastos, afetando o ritmo e a natureza do processo de acumulação de capital.

\footnotetext{
${ }^{1}$ A moeda tornou-se a base para contratos em virtude da relativa estabilidade de seu valor, decorrente de suas características de negligíveis elasticidades de produção e de substituição. Sobre este ponto, ver Keynes (1988a, cap .17), Amado (2000).

${ }^{2}$ A concepção de incerteza "faz da moeda um ativo, a despeito de ela não render juro" (Studart, 1995, p. 28).
}

${ }^{3}$ Sobre o estado da expectativa a longo prazo, ver Keynes (1988a, cap. 12). 


\section{Investimento e poupança}

Em economias monetárias o nível do investimento é sensível ao grau de incerteza e às expectativas a ele associadas, e depende da comparação entre a eficiência marginal do capital (emc) e a taxa de juros ${ }^{4}$. A emc refere-se à taxa de retorno do investimento. Ainda, Keynes salienta o caráter subjetivo dessa taxa.

Ademais, o financiamento do investimento não se dá mediante poupança prévia. Em economias monetárias prevalece o circuito Finance-Investimento-Poupança-Funding. O investimento antecede a poupança que, por seu turno, resulta do crescimento econômico. O papel da poupança é consolidar (mas não financiar) a acumulação de capital, reduzindo a instabilidade financeira que acompanha o crescimento e proporcionando-lhe sustentabilidade (Keynes, 1988b, c; Studart, 1995).

O finance motive corresponde ao crédito de curto prazo demandado pelas firmas no intervalo de tempo entre a decisão do investimento e sua implementação. A poupança agregada surge após a implementação do investimento agregado, via multiplicador dos gastos, e é usada para transformar a dívida de curto prazo dos investidores junto ao sistema bancário em passivo de longo prazo. O funding corresponde ao processo de "consolidar" a dívida de curto prazo: transformá-la numa relação de longo prazo através da emissão de ações e títulos. Assim, poupança e financiamento da despesa do investimento não se confundem, necessariamente.

A taxa de juros, por sua vez, não depende da poupança. Ela é um fenômeno monetário e se relaciona inversamente com o investimento. A taxa de juros não é a retribuição "pela espera para consumir" e, sim, pela renúncia à liquidez. O juro é determinado pela preferência pela liquidez e pela oferta de moeda, esta última determinada pela política monetária e pelas estratégias de crédito dos bancos. A oferta de moeda tem um caráter endógeno, pois bancos também estão sujeitos à incerteza e possuem preferência pela liquidez ${ }^{6}$.

\footnotetext{
4 "O leitor notará que a eficiência marginal do capital é definida aqui em termos da expectativa da renda e do preço de oferta corrente do bem de capital. Ela depende da taxa de retorno que se espera obter do dinheiro investido num bem recentemente produzido". Keynes (1988a, p. 101). Conforme Keynes (1988a, p. 101), "defino a eficiência marginal do capital como sendo a taxa de desconto que tornaria o valor presente do fluxo de anuidades das rendas esperadas desse capital, durante toda a sua existência, exatamente igual ao seu preço de oferta". O preço de oferta de um bem de capital é o valor exatamente suficiente para que o empresário considere vantajoso produzir uma unidade a mais do mesmo. Segundo Chick (1993, p. 267), “Um investimento sem a expectativa de poder gerar fluxo de caixa para pagar juros e prover o seu próprio fundo de amortização para amortizar o principal não é levado a cabo: é esse é que é, em toda parte, o critério de igualdade entre a emc (eficiência marginal do capital) e $r$ (taxa de juros)".

5 “A taxa de juros é o preço mediante o qual o desejo de manter a riqueza em forma líquida se concilia com a quantidade de moeda disponível” (Keynes, 1988a, p. 120).

${ }^{6} \mathrm{O}$ Banco Central cria reservas através de operações de mercado aberto. Todavia, o repasse dessas reservas dos bancos para o público não é automático. Conforme a incerteza percebida pelos bancos,
} 


\section{POLÍTICA MONETÁRIA E DECISÕES DE INVESTIMENTO EM ECONOMIAS MONETÁRIAS}

$\mathrm{Na}$ economia monetária o equilíbrio macroeconômico pode se dar com um nível do produto aquém do nível de pleno emprego ${ }^{7}$. Enquanto o consumo é uma função estável da renda, o investimento não está relacionado à renda corrente. Ele depende da demanda esperada no futuro e das taxas de juros correntes. Mas o futuro é incerto, sendo impossível o cálculo de probabilidades para eventos econômicos associados a longos horizontes temporais, como é o caso do investimento. Daí decorre seu caráter especulativo.

Os empresários irão buscar o lucro monetário máximo, "esforçando-se por fixar o volume de emprego ao nível em que esperam maximizar a diferença entre a receita e o custo dos fatores" (Keynes, 1988a, cap. 3). Visto que o consumo é uma função crescente do emprego, a demanda agregada também o é. Porém, ela não é coincidente com a oferta agregada - que também é uma função crescente do emprego - porque as despesas de investimento dependem das expectativas de demanda no futuro. A demanda agregada futura pode ser maior ou menor por ser a moeda um ativo alternativo. Assim, só há um ponto na curva de oferta agregada onde a maximização esperada do lucro se verifica. Este ponto é chamado demanda efetiva.

Portanto, a política monetária possui papel ativo na economia. Ela deve acomodar a demanda por moeda para transação, que, por sua vez, é uma função estável da renda (Keynes, 1988a, cap. 15). Tal política deve, também, impedir que mudanças no estado da preferência pela liquidez afetem os preços de ativos não líquidos (Carvalho, 1992a, cap. 12). Isto é, a política monetária deve isolar a taxa de juros dos efeitos que incidem sobre esta mesma taxa, provocados por mudanças na demanda de moeda (pelos motivos precaução e especulação), que decorrem de alterações na incerteza percebida pelos agentes. Dada a oferta de moeda, aumentos na demanda por moeda (elevações da preferência pela liquidez) pressionarão para cima a taxa de juros monetária. O aumento da taxa de juros desestimula o inves-

estes podem contrair a oferta de crédito no âmbito da administração do lado do ativo de seus balanços, se contrapondo à política monetária do Banco Central. Entre as Autoridades Monetárias e o público estão os bancos, que procuram conciliar a busca de lucratividade com sua escala de preferência pela liquidez. Ainda, Minsky (1986) demonstrou que por meio da administração de seus passivos, o que inclui as chamadas inovações financeiras, bancos podem adotar uma política mais agressiva de captação de fundos e contornar restrições impostas pela Autoridade Monetária, ampliando a oferta de crédito. Assim, a Autoridade Monetária não tem controle absoluto sobre a oferta de moeda devido à intermediação bancária que se interpõe entre ela e o público. Portanto, a oferta de moeda é endógena. Isto não quer dizer que a oferta de moeda seja horizontal (totalmente endógena). Ver detalhes em Carvalho (1993) e Paula (1999).

\footnotetext{
${ }^{7}$ Keynes usou a "velha" função de oferta clássica da concorrência perfeita como microfundamento da função de oferta agregada (Davidson, 1999). O caso geral de equilíbrio com desemprego involuntário seria consequência de problemas do lado da demanda.
} 
timento. Cabe à política monetária evitar este quadro ${ }^{8}$. Todavia, a política monetária não age diretamente sobre o produto na circulação industrial e, assim, sua eficácia é relativa9.

Quando a política monetária é "eficaz", sua influência sobre a decisão de investimento se dá não apenas em função de alterações na taxa de juros, que é um parâmetro para a magnitude da emc no processo de tomada de decisão de investimento. Tal política também afeta o investimento através de sua influência sobre a demanda efetiva. Uma política monetária contracionista pode levar a uma alteração na incerteza percebida pelos agentes, provocando mudanças na preferência por sua liquidez e no nível da demanda esperada no futuro. Como o investimento depende da demanda esperada e das taxas de juros correntes, ele será afetado pela política monetária.

\section{Inflação, expectativas de política monetária e investimento}

$\mathrm{Na}$ abordagem pós-keynesiana a política monetária restritiva pode implicar queda da emc concomitantemente ao aumento das taxas de juros, desestimulando o investimento e o crescimento econômico. A trajetória dessas variáveis seria então afetada, inclusive no longo prazo, dado o caráter não-neutro da moeda. Ainda, expectativas de adoção de política monetária apertada poderiam produzir resultados semelhantes, tendo em vista as decisões dos agentes econômicos de recomposição de portfolio, que dependem de seus cálculos subjetivos sobre contextos futuros. A Expectativa de adoção de política monetária restritiva produziria efeitos deletérios sobre a emc, deprimindo a taxa de investimento.

Entretanto, essa relação entre política monetária e investimento, observada na abordagem pós-keynesiana, não é compatível com o referencial teórico ortodoxo. Segundo Mollo (2004), a linha divisória entre ortodoxia e heterodoxia econômicas é traçada a partir do conceito de neutralidade da moeda. Enquanto na heterodoxia

\footnotetext{
${ }^{8}$ A combinação das políticas fiscal, de rendas e monetária permitiria uma adequada administração macroeconômica no sentido de manter o pleno emprego e a estabilidade de preços (Carvalho, 1999, cap. 12; Sicsú, 2007).

${ }^{9}$ Segundo a escola pós-keynesiana, a moeda teria duas leis de circulação: a circulação industrial e a circulação financeira. Na primeira, a moeda é meio de troca, girando bens e serviços. Na circulação financeira a moeda gira ativos, sendo ela mesma um ativo alternativo. A eficácia da política monetária em estimular o investimento e o emprego depende não apenas das ações das autoridades monetárias, mas, também, das decisões de recomposição de portfolio dos diversos agentes. A política monetária favorece o investimento quando induz vazamentos da moeda da circulação financeira para a industrial. Ao mudar a taxa de juros, tal política afeta a relação entre os diversos ativos da economia (inclusive a moeda) que o público deseja manter. Entretanto, as decisões de recomposição de portfólio dependem de cálculos subjetivos sobre contextos futuros, realizados pelos agentes tais como bancos, firmas e indivíduos. Um aumento da preferência pela liquidez pode, por exemplo, impedir os vazamentos da moeda da circulação financeira para a industrial (Carvalho et al., 2001 pp. 171-173).
} 
econômica a moeda seria não-neutra, nas escolas econômicas ortodoxas ela é considerada neutra, pelo menos no longo prazo.

Se a moeda é neutra, a política monetária não poderia afetar o processo de acumulação de capital. Neste caso, vale a dicotomia clássica, segundo a qual a moeda não afeta o lado real da economia. Ou seja, no âmbito da ortodoxia econômica não seria válida a relação entre política monetária e investimento, postulada neste estudo a partir da abordagem pós-keynesiana. Aceitar a neutralidade da moeda implica aceitar a validade da Lei de Say e da teoria quantitativa da moeda (Mollo, 2004). Neste contexto da ortodoxia econômica foi desenvolvido o sistema de metas de inflação.

\section{METAS DE INFLAÇÃO, POLÍTICA MONETÁRIA E INVESTIMENTO NA ORTODOXIA ECONÔMICA}

Quando a moeda é um véu, cuja função é a de meio de troca, sua neutralidade é observada. Neste contexto, Lucas $(1972,1973,1981)$ demonstrou que a política monetária enseja oscilações de curto prazo do produto real em torno de sua trajetória de longo prazo quando as informações são imperfeitas e os agentes possuem “expectativas racionais" ${ }^{10}$. A política monetária expansionista provocaria inflação e, dado o limitado conjunto de informações dos agentes no curto prazo, estes confundiriam aumento geral de preços com mudanças de preços relativos. A resposta ótima dos agentes à mudança de preços relativos percebida (equivocadamente) seria posteriormente revertida quando os agentes constatassem o problema da extração de sinal. A hipótese de informação imperfeita implicaria na não-neutralidade da moeda no curto prazo, embora esta fosse neutra no longo prazo ${ }^{11}$.

Sendo a moeda não-neutra no curto prazo, Barro e Gordon (1994) argumentam que em um regime discricionário a inflação não esperada pelos agentes, decorrente de emissão monetária, permitiria a expansão da atividade econômica e a redução do desemprego e do valor real do passivo público. Porém, este tipo de surpresa não poderia ocorrer sistematicamente em equilíbrio, já que os agentes entendem os incentivos dos formuladores de política. A sistemática expansão mo-

\footnotetext{
${ }^{10}$ Segundo Lucas (1981, p. 223), John Muth sugeriu que os agentes possuem expectativas racionais quando identificam suas probabilidades subjetivas com as frequências observadas de eventos a serem previstos, ou seja, quando as probabilidades subjetivas dos agentes são coincidentes com as "verdadeiras" probabilidades de eventos futuros.

${ }^{11}$ Lucas (1973) estimou um modelo de equilíbrio entre oferta e demanda visando testar a hipótese de que no curto prazo a moeda seria não-neutra em um contexto de informações imperfeitas, e, neste caso, produto real e preços se moveriam na mesma direção, no curto prazo. A especificação das equações estimadas e a metodologia utilizada em Lucas (1973) e os resultados encontrados estão apresentados no Apêndice deste artigo.
} 
netária acima do esperado implicaria taxas de inflação cada vez maiores, ensejando custos igualmente maiores.

$\mathrm{Na}$ medida em que os agentes possuem expectativas racionais, quando os formuladores de política possuem boa reputação (credibilidade) a inflação esperada pelo público converge para a inflação anunciada. Porém, para alcançar boa reputação, as políticas devem ser anunciadas e rigorosamente seguidas - o governo não pode trapacear, incorrendo em inconsistência dinâmica. Barro e Gordon (1994) concluem que o regime de regras de política monetária é superior ao regime discricionário.

O regime de metas de inflação (doravante $\mathrm{MI}$ ), se ajusta ao argumento de Barro e Gordon (1994). Tal regime consiste na definição e divulgação oficial de uma meta para determinado índice de inflação e o comprometimento da autoridade monetária (AM) em perseguir tal meta ${ }^{12}$. "Assim, tais metas coordenam a formação de expectativas inflacionárias dos agentes e a fixação de preços e salários” (Ferreira, 2004, p. 20). Deste modo, ao invés de adotar regras fixas para a emissão de moeda, no regime de MI a inflação seria fixada publicamente e a política monetária adotada seria aquela necessária para se alcançar a meta de inflação $0^{13}$.

Num contexto de boa reputação da AM, quando surgem pressões empurrando a inflação para além da meta estabelecida, os agentes econômicos, cientes do compromisso da AM, convergirão suas expectativas para a meta de inflação proposta e o equilíbrio macroeconômico será mantido. Isto ocorre como resultado do processo de maximização dos agentes no contexto em que estes creem no compromisso da AM de perseguir a meta de inflação anunciada. Desde que o governo tenha credibilidade, não há trade-off entre inflação e desemprego.

Todavia, muitas vezes a credibilidade do governo é baixa. Neste caso, os agentes (racionais) terão maior dificuldade em convergir sua inflação esperada para a meta anunciada. Assim, os custos envolvidos no combate à inflação, como é o caso do desemprego, serão mais elevados até os formuladores de política alcançarem boa reputação. Ainda, tais custos verificam-se apenas no curto prazo $^{14}$. Conforme o Banco Central (1999),

\footnotetext{
${ }^{12}$ A estratégia da autoridade monetária para alcançar tal objetivo contempla elementos como: a) compromisso com a meta de inflação estipulada; b) transparência nas ações; c) comunicação constante com os agentes econômicos. O regime de metas de inflação foi inicialmente implementado na Nova Zelândia, em 1990.

${ }^{13} \mathrm{O}$ regime de metas teria maior flexibilidade em relação ao regime de regras e seria superior ao regime discricionário (Bernanke et al., 1999; Mishkin, 2001). Para mais detalhes sobre o regime de metas de inflação, ver Mishkin (2001, 2004), Bernanke et al. (1999) e Svensson (1998).

14 "É a aceitação da neutralidade que justifica a prioridade de controle de preços sobre a garantia do crescimento econômico. Nestas concepções o mercado é o regulador mais eficiente e é preciso, por isso, garantir que os preços relativos não fiquem distorcidos por processos inflacionários (...) como a moeda é neutra, o crescimento não é percebido como muito comprometido. No máximo será de forma transitória. É esta neutralidade (...) da moeda sobre a economia real que torna mais fácil, para seus defenso-
} 
“(...) o objetivo principal da política monetária deve ser a obtenção e manutenção da estabilidade de preços (...) é importante notar que a política monetária produz efeitos reais apenas no curto e médio prazos, ou seja, no longo prazo, a moeda é neutra. O único efeito existente no longo prazo é sobre o nível de preços da economia.”

Portanto, o regime de MI foi erigido sob a hipótese de neutralidade da moeda. Esta não poderia afetar o processo de acumulação de capital, isto é, a trajetória de longo prazo do investimento, segundo a abordagem ortodoxa. Nesta abordagem, o regime de MI e a política monetária a ele associada não teriam efeito algum sobre o investimento e o crescimento no longo prazo. As expectativas dos agentes (racionais) sobre a política monetária poderiam, inclusive, num contexto de credibilidade da AM, facilitar a convergência da inflação esperada com a meta de inflação, amenizando os distúrbios (de curto prazo) causados pela inflação num sistema com informações imperfeitas. Estas conclusões são opostas àquelas elaboradas a partir do referencial teórico pós-keynesiano. Na próxima seção será testada a hipótese de (não-) neutralidade da moeda.

\section{O MODELO DE INVESTIMENTO}

Para testar a hipótese de não-neutralidade da moeda, no âmbito do regime de MI, será desenvolvido e estimado, a seguir, um modelo de investimento.

\section{$\mathrm{O}$ acelerador do investimento}

O modelo do acelerador do investimento se baseia na relação observada entre a taxa de investimento e alterações no nível de atividade econômica. Considera-se que a quantidade desejada de capital $\left(\mathrm{K}^{*}\right)$ é uma fração constante $(\mathrm{h})$ da produção (Y): $K^{*}=h Y(1)$. O investimento líquido (I) seria: $I_{t+1}=K^{*}{ }_{t+1}-K_{t}$ (2); $I_{t+1}=h Y_{t+1}-h Y_{t} \quad$ (3); $I_{t+1}=h\left(Y_{t+1}-Y_{t}\right) \quad$ (4), onde $\mathrm{K}=$ estoque de capital ${ }^{15}$.

\section{Taxa Real de Juros e Investimento}

Segundo Keynes (1988a, cap. 11), há uma correlação negativa entre investimento e taxa de juros. Assim, espera-se que o coeficiente estimado da taxa de juros real no modelo de investimento seja negativo. A taxa de juros real será calculada como em Greene e Villanueva (1991).

\footnotetext{
res, a proposição de controle monetários restritivo para a redução da inflação, uma vez que custos sociais envolvidos não tendem a ser encarados como elevados" (Mollo, 2004, p. 3).

${ }^{15}$ Apesar das limitações, segundo Sachs e Larrain (1995, p. 150) o modelo do acelerador é, em geral, melhor que outros para explicar e prever os padrões de investimento.
} 


\section{Crédito e investimento}

Conforme Keynes e pós-keynesianos, na economia monetária prevalece o circuito Finance-Investimento-Poupança-Funding. O finance foi definido anteriormente e é pré-condição para o investimento. $\mathrm{O}$ crédito bancário será usado como proxy para o motive finance no modelo a ser estimado. Espera-se encontrar uma correlação positiva entre o volume de crédito bancário transferido ao setor priva$\mathrm{do}^{16} \mathrm{e}$ o investimento.

\section{Expectativas de política monetária e investimento}

Conforme a equação (4), o investimento cresce à medida que a produção aumenta. Porém, o modelo do acelerador não considera as alterações no custo de capital (variações nas taxas de juros). Não considera, também, as expectativas quanto ao retorno do investimento, o que lhe confere um caráter mecânico. Mas, conforme abordado na primeira seção, a emc é definida em termos da expectativa da renda (retorno) e do preço de oferta corrente, do bem de capital. Na economia monetária, expectativas não passíveis de cálculos probabilísticos sobre o retorno do investimento são fundamentais para a determinação das decisões de investir. Assim, optou-se por incorporar um elemento de expectativas no modelo do investimento.

Baseando-se na escola pós-keynesiana, propõe-se uma equação que considera o investimento função das expectativas de demanda (efetiva), entre outros fatores. Estas expectativas, por sua vez, são influenciadas pela resposta esperada da política monetária às variações do nível de preços. Assim, a política monetária é capaz de influenciar o investimento por meio de dois canais: a) ao afetar a demanda agregada e, portanto, as expectativas de retorno do investimento, a política monetária afeta a emc; b) ao determinar a taxa de juros que remunera importante ativo da economia, a saber, títulos do Tesouro Nacional, a política monetária afeta o que Keynes (1988a) denominou de "complexo de taxa de juros", com efeitos sobre as decisões de investimento, visto que estas dependem da comparação entre emc e a taxa própria de juros dos ativos alternativos a um determinado bem de capital ${ }^{17}$.

Parte-se da suposição de que quanto maior for a inflação observada, maior será a contração esperada da oferta de moeda, ensejada pela AM. Portanto, diante de uma pressão inflacionária cresce a expectativa dos agentes de um aumento da taxa básica de juros da economia. A consequência seria a queda do investimento,

\footnotetext{
${ }^{16} \mathrm{O}$ dado do IFS utilizado para a variável crédito foi o crédito doméstico na abordagem bancária (“bank survey”). Esses dados de crédito estão disponíveis para todos os países em análise.

${ }^{17}$ Sobre o conceito de taxa própria de juros e sobre a teoria de escolha de ativos, ver Keynes (1988, cap. 17) e Carvalho (1992a, cap. 5).
} 
não apenas em função do aumento esperado da taxa de juros, mas, também, devido à retração esperada na demanda efetiva decorrente do próprio aumento futuro (esperado) da taxa de juros. Nesse sentido, a diferença entre o nível de preços corrente e o nível de preços passado será utilizada como proxy para a expectativa quanto ao retorno esperado do investimento. Portanto, o modelo do investimento a ser estimado através de dados em painel torna-se:

$$
I_{i, t}=\alpha_{1 i}+\alpha_{2}\left(G D P_{i t}-G D P_{i t-1}\right)+\alpha_{3} C R E D_{i t}+\alpha_{4} T R J+\alpha_{5}\left(I P_{i t}-I P_{i t-1}\right)+\varepsilon_{i t}
$$

Onde, I = investimento agregado; $\mathrm{GDP}_{\mathrm{it}}-\mathrm{GDP}_{\mathrm{it}-1}=$ variação do produto doméstico bruto; CRED = crédito bancário; TJR = taxa de juro real; $\mathrm{IP}_{\mathrm{it}}-\mathrm{IP}_{\mathrm{it}-1}(\mathrm{ou}$, $\mathrm{VIP})=$ variação do índice de preços; $\alpha_{1}, \alpha_{2}, \alpha_{3}, \alpha_{4}$ e $\alpha_{5}$ são parâmetros da equação. $\mathrm{O}$ índice $\mathrm{i}$ indica os países que adotam o regime de MI e o índice $t$ indica os anos considerados - dimensão de corte transversal e temporal dos dados de painel, respectivamente. $\mathrm{O}$ coeficiente $\alpha_{1 i}$ representa o efeito não observado do país ou efeito fixo país - os fatores não observados que afetam o investimento e que não mudam ao longo do tempo. A variável $\varepsilon_{i t}$ representa o erro idiossincrático ou erro de variação temporal - incorpora os fatores não observados que mudam ao longo do tempo e que afetam o investimento.

Para o caso da adoção do regime de MI, que pressupõe as características de credibilidade e transparência, a AM teria um compromisso explícito em perseguir a meta de inflação estabelecida e, portanto, na ótica pós-keynesiana, espera-se um valor negativo para o coeficiente estimado $\alpha_{5}\left(\alpha_{5}<0\right)$. Assim, haveria uma correlação negativa entre os valores contemporâneos da inflação e do investimento. $\mathrm{O}$ aumento da inflação induziria o surgimento de expectativas de aplicação de política monetária contracionista, no âmbito do regime de MI, inibindo o investimento. Expectativas de política monetária restritiva (no futuro), por si sós, poderiam implicar aumentos na preferência pela liquidez dos agentes e a redução da emc, deprimindo a taxa de investimento corrente (Resende e Lima, 2007).

Entretanto, antes da adoção do regime de MI não se espera, necessariamente, um coeficiente $\alpha_{5}$ negativo, visto que não haveria um compromisso da AM em atingir uma determinada meta inflacionária, pois a moeda não seria neutra e a política monetária poderia afetar os níveis do produto e do emprego - não haveria um compromisso explícito do Banco Central de combater de forma rigorosa a inflação dados os custos sociais envolvidos nesse processo. Dependendo do contexto econômico e político de cada país, a política de combate à inflação poderia ser prioritária ou não. Além disso, visando combater a inflação o governo poderia adotar, por exemplo, políticas de rendas, ao invés de política monetária restritiva ${ }^{18}$. Portanto, não haveria uma correlação negativa e sistemática entre os valores con-

\footnotetext{
${ }^{18}$ De acordo com pós-keynesianos, há outros instrumentos de política eficazes no combate à inflação, além da política monetária (Sicsú, 2007, cap. 5).
} 
temporâneos do investimento e da inflação no período anterior ao da implementação do regime de MI.

Justifica-se, assim, a inclusão de uma dummy piece-wise ${ }^{19}$ para a variável IP $_{\text {it }}$

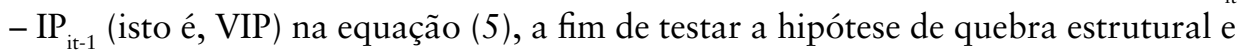
de mudança no sinal do coeficiente de VIP, a partir da adoção do regime de MI. Espera-se que o coeficiente estimado da dummy piece-wise seja significantemente negativo, o que implica o surgimento de uma correlação negativa entre os valores contemporâneos do investimento e da inflação após a adoção do regime de MI, se a abordagem pós-keynesiana for correta. Com a inclusão da dummy piece wise, DPWIP, tem-se o seguinte modelo de investimento:

$$
I_{i, t}=\alpha_{1 i}+\alpha_{2}\left(G D P_{i t}-G D P_{i t-1}\right)+\alpha_{3} C R E D_{i t}+\alpha_{4} T R J+\alpha_{5}\left(I P_{i t}-I P_{i t-1}\right)+\alpha_{6} D P W I P_{i t}+\varepsilon_{i t}
$$

Onde, DPWIP = variável dummy piece wise cujo valor é não nulo a partir da adoção do regime de MI. Nesse modelo, antes da ruptura (implantação do regime de metas), a inclinação de VIP é $\alpha_{5}$, mas ela muda para $\alpha_{5}+\alpha_{6}$ após a ruptura. Assim, $\alpha_{6} D P W I P_{i t}=\alpha_{6}\left(V I P_{i t}-V I P_{i t 0}\right) D_{i t}$, onde VIP $i t 0$ é o diferencial de preços no momento da quebra estrutural (período da implantação do regime de metas para cada país i) e $\mathrm{D}_{\text {it }}$ assume os valores 1 , se $\mathrm{t}=$ ito ou $\mathrm{t}>$ ito, e 0 , se $\mathrm{t}<$ ito. O instante ito seria o momento da implantação do regime de MI em cada país i. Em suma, se após a implantação do regime de MI o coeficiente $\alpha_{7}=\left(\alpha_{5}+\alpha_{6}\right)<0$, poder-se-á concluir que há uma correlação negativa entre os valores contemporâneos do investimento e da inflação. Esse resultado corroboraria o paradigma teórico pós-keynesiano ${ }^{20}$.

Se na perspectiva pós-keynesiana há uma correlação negativa entre os valores contemporâneos da inflação e do investimento no âmbito do regime de MI, para a ortodoxia econômica tal correlação não existe. Se a moeda é neutra, a política monetária contracionista necessária para se atingir a meta de inflação desejada pressupõem que o produto não será afetado no longo prazo. No máximo, este será afetado no curto prazo, porém, o investimento, o produto e o emprego não seriam afetados pela política monetária no ato de sua implementação. Para a corrente ortodoxa há defasagens temporais (defasagens interna e externa) entre a inflação, a adoção de uma determinada política monetária e seus efeitos sobre a demanda agregada, o produto e os preços (Friedman, 1968). Assim, não haveria,

\footnotetext{
${ }^{19}$ Uma descrição da técnica piece wise pode ser encontrada em Pindyck e Rubenfeld (2004, cap. 5).

${ }^{20} \mathrm{Na}$ abordagem pós-keynesiana a variável crédito estimula o investimento e é estimulada por este. Isto pode provocar um problema de simultaneidade para a estimação da equação 6 . Para solucionar este problema, a equação de investimento foi estimada utilizando-se o método de variáveis instrumentais com a adoção da variável crédito defasada em um período. Os resultados desta estimação são muito semelhantes àquele encontrado a partir da estimação da equação 6 , razão pela qual optou-se por estimar a equação de investimento conforme a especificação da equação 6 .
} 
segundo a ortodoxia, uma correlação negativa entre os valores contemporâneos do diferencial de preços e do investimento no contexto do regime de MI.

Portanto, pode-se estabelecer quatro contextos teóricos básicos quando se pretende extrair os sinais dos coeficientes $\alpha_{5}$ e $\alpha_{6}$ da equação (6): dois desses contextos correspondem à visão pós-keynesiana da relação entre inflação e investimento antes e após a adoção do regime de MI. Os outros dois contextos seriam a visão ortodoxa da relação entre inflação e investimento antes e após a adoção deste regime. Os dois primeiros contextos já foram explanados - após a adoção do regime de MI $\alpha_{7}=\left(\alpha_{5}+\alpha_{6}\right)<0$, implicando a adequação da teoria pós-keynesiana.

Porém, se o coeficiente $\alpha_{7}=0$ ou $\alpha_{7}>0$, ter-se-á uma evidência favorável ao modelo ortodoxo, anteriormente apresentado. De acordo com a ortodoxia econômica, não se espera que o parâmetro $\alpha_{7}$ seja negativo, ou seja, espera-se um coeficiente positivo ou nulo, seja antes ou depois da adoção do regime de MI. Uma abordagem que justifica essa correlação não negativa seria a novo-clássica. Segundo a curva de oferta de Lucas $(1972,1981)$, uma política monetária somente poderia afetar o produto real no curto prazo se não for antecipada. No longo prazo a curva de oferta seria vertical. No curto prazo os agentes econômicos se deparariam com o problema de extração de sinal. Diante de uma inflação não esperada, os agentes interpretariam parte do aumento do nível geral dos preços como aumento do preço relativo dos seus produtos e aumentariam a produção. O produto no curto prazo varia no mesmo sentido do nível dos preços diante de uma inflação não esperada. Nas situações em que a informação é perfeita, ou no longo prazo (os agentes são capazes de extrair o sinal), não haveria correlação entre produto e inflação. Estes mesmos argumentos seriam válidos para a correlação entre inflação e investimento, conforme Lucas (1981). Ou seja, o coeficiente $\alpha_{7}$ seria positivo. Mesmo antes da adoção do regime de MI o coeficiente de VIP seria positivo no curto prazo e nulo no longo prazo (idem) ${ }^{21}$. Portanto, inicialmente, ou contemporaneamente, preços e investimento devem se mover na mesma direção, tornando $\alpha_{7}>0$.

\footnotetext{
${ }^{21}$ Conforme Lucas (1981), na presença de informação imperfeita o produtor se deparará com o problema de extração de sinal: "ele observa uma única variável (preço) mudando através do tempo; estes movimentos surgem de movimentos em variáveis mais fundamentais (os componentes transitórios e permanentes do preço), as quais não podem ser observadas diretamente (...) partindo da observação desses movimentos de preços (...) ele (produtor) infere de modo imperfeito o movimento nestes dois componentes (...) a resposta para um aumento de preços imprevisto é o aumento na oferta de trabalho, uma queda no estoque de bens finais e uma expansão da acumulação de capital produtivo" (Lucas, 1981, pp. 227 228). Ainda, “(...) movimentos de preços relativos permanentes e transitórios não podem ser classificados com certeza em um dado momento, e movimentos gerais e relativos não podem ser distinguidos. Aumento geral de preços, assim como ocorreria com aumento de preços relativos, induzirá o emprego e o investimento a se moverem na mesma direção (...) ademais, há uma retração automática na expansão da capacidade. Quando há o reconhecimento de que houve um aumento geral de preços, o investimento terá de ser reduzido a um nível abaixo de seu nível normal até que a capacidade (instalada da economia) se ajuste para baixo (...) este cenário, assim como descrito inicialmente para a resposta do emprego, depende crucialmente da confusão de parte dos agentes entre mudança geral de preços e mudança de preços relativos. Isto é especialmente claro no caso do investimento (...) ” (Lucas, (1981. pp. 230-231).
} 
Somente em um período posterior, "quando há o reconhecimento de que houve um aumento geral de preços", este fenômeno é revertido, produzindo-se a fase descendente do ciclo econômico.

Os sinais dos coeficientes $\alpha_{5}, \alpha_{6}$ e $\alpha_{7}$ também podem ser identificados pela abordagem teórica de credibilidade de políticas monetárias. Neste caso, poder-se-ia considerar quatro situações na teoria mainstream com relação ao comportamento da AM quando a inflação é ascendente. O Quadro 1 resume esses comportamentos e é válido seja para o período anterior, seja para o período posterior à adoção do regime de MI.

$\mathrm{Na}$ visão ortodoxa, uma política discricionária expansionista implica surpresas monetárias aos agentes econômicos no intuito do policymaker de obter benefícios no curto prazo em termos de produto e emprego. Mas, no futuro, os agentes econômicos incorporam sobre suas decisões expectativas inflacionárias, o que leva a economia para uma posição de equilíbrio à taxa natural de desemprego e com uma inflação mais elevada (Kydland e Prescott, 1977).

Quadro 1: Comportamentos da autoridade monetária - abordagem mainstream

\begin{tabular}{|c|c|c|c|}
\hline \multicolumn{2}{|c|}{$\begin{array}{c}\text { Autoridade Monetária (AM) } \\
\text { com Credibilidade }\end{array}$} & \multicolumn{2}{c|}{$\begin{array}{c}\text { Autoridade Monetária (AM) } \\
\text { sem Credibilidade }\end{array}$} \\
\hline $\begin{array}{c}\text { AM blefa e não adota } \\
\text { política monetária } \\
\text { contracionista. }\end{array}$ & $\begin{array}{c}\text { AM não blefa e não adota } \\
\text { política monetária contracio- } \\
\text { nista - não há trade-off entre } \\
\text { inflação e desemprego }\end{array}$ & $\begin{array}{c}\text { AM blefa e não adota } \\
\text { política monetária } \\
\text { contracionista. }\end{array}$ & $\begin{array}{c}\text { AM não blefa (busca } \\
\text { credibilidade) e adota } \\
\text { política monetária } \\
\text { contracionista. }\end{array}$ \\
\hline
\end{tabular}

Fonte: Resende e Lima (2007).

Uma política considerada ótima anunciada em t poderia não ser consistente temporalmente. Levando-se em conta as expectativas racionais dos agentes, estes anteveriam que a política anunciada não maximizaria a função de bem-estar (política não crível) e, portanto, não adotariam suas decisões de acordo com a política econômica anunciada. Assim, tal política seria ineficiente, pois os agentes não agiriam em consonância com o policymaker (Kydland e Prescott, 1977).

Ou seja, uma AM sem credibilidade, ao anunciar uma determinada política monetária contracionista, poderia estar blefando. A AM poderia ter incentivos de perseguir outros objetivos, como elevar o produto e o emprego. De outro lado, os agentes, tomando por base suas expectativas racionais, teriam conhecimento do incentivo da AM em trapacear e incorporariam em suas decisões uma expectativa de inflação mais alta. O resultado seria uma inflação maior e sem obter um nível mais alto do produto (Kydland e Prescott, 1977; Barro e Gordon, 1983). Portanto, uma AM sem credibilidade pode blefar e adotar política monetária expansionista mesmo num contexto de preços em ascensão, embora autores como Kydland e Prescott (1977) argumentem que tal política seja ineficiente. Este resultado está no terceiro quadrante do Quadro 1 (a AM blefa e não adota política monetária contracionista) e pode ocorrer antes ou depois da adoção do regime de MI. Após a 
adoção deste regime, a AM poderia blefar se as tecnologias de comprometimento forem fracas ou falhas.

Mesmo para o caso da adoção de política de regras, onde a AM poderia ter credibilidade, pode haver um viés inflacionário caso não haja tecnologias de comprometimento, pois podem existir incentivos ao rompimento da regra (a AM trapacearia). Ou seja, para a AM os benefícios decorrentes do rompimento da regra para reduzir o desemprego corrente poderiam ser maiores do que os custos em gerar uma inflação maior. Assim, uma regra monetária pode ser crível inicialmente, mas os mecanismos de comprometimento podem ser falhos, levando à perda de credibilidade da política monetária. Ou, então, uma regra monetária pode não ser crível em economias sem tecnologias de compromisso (Barro e Gordon, 1983; Kydland e Prescott, 1977). Portanto, a AM, mesmo possuindo credibilidade inicialmente, poderia blefar visando a um maior nível de produto e emprego (Resende e Lima, 2007). Este resultado está no primeiro quadrante do Quadro 1 (a AM blefa e não adota política monetária contracionista).

Quando a AM busca credibilidade, repetidas interações entre a AM e os agentes econômicos podem criar forças reputacionais, as quais fornecem suporte à adoção de uma política monetária contracionista. Uma potencial perda de reputação pode motivar a AM a seguir a política estabelecida. Haveria, adicionalmente, o custo da perda de reputação, que, por sua vez, pode superar os benefícios advindos da opção de blefar. Assim, a AM abdicaria dos benefícios de curto prazo (produto e emprego) em prol de poder assegurar ganhos de uma inflação menor no longo prazo, além de manter sua credibilidade (Barro e Gordon, 1983). Portanto, uma AM sem credibilidade, em sua estratégia de obter credibilidade e boa reputação junto aos agentes econômicos, pode adotar políticas monetárias contracionistas (não blefando) quando a inflação é ascendente. Este resultado está no quarto quadrante do Quadro 1 (a AM não blefa - busca credibilidade - e adota política monetária contracionista).

Nesse último caso, deve ocorrer uma correlação entre pressão inflacionária e política monetária contracionista e outra correlação entre inflação e investimento. Porém, essas correlações não são contemporâneas. Na ortodoxia econômica, os efeitos da política monetária sobre o investimento se verificam com defasagem temporal. Haveria uma defasagem entre a necessidade da ação e o reconhecimento da necessidade de agir, outra entre a necessidade de agir e a ação e, por último, entre a ação e seus efeitos (Friedman, 1968). O investimento corrente não dependeria das conjeturas sobre o nível da demanda agregada futura formadas num contexto de expectativas não ergódicas. Isto é, de acordo com a corrente ortodoxa, os agentes não precisam conjeturar sobre eventos econômicos futuros para decidir sobre o investimento hoje, visto que já conhecem previamente a distribuição de probabilidades de tais eventos. Os agentes maximizam suas funções objetivo conhecendo previamente a distribuição de probabilidades dos eventos futuros - as decisões de investir dos agentes são reflexos de maximizações de funções de utili- 
dade à luz de expectativas racionais. A correlação entre diferencial de preços e investimento se dará apenas quando os agentes forem surpreendidos pela política monetária, porém os efeitos da política monetária sobre a economia se dão com hiatos temporais. Nesse contexto de "expectativas racionais" não há vínculos entre a decisão corrente de investir e a expectativa corrente de aplicação de política monetária restritiva. Assim, a correlação entre os valores correntes da inflação e do investimento não seria negativa (Resende e Lima, 2007).

Por fim, pode-se argumentar, com base em Barro e Gordon (1983), que após a implantação do regime de MI, segundo o qual há tecnologias de comprometimento e os formuladores de política têm credibilidade, o aumento da inflação não deve provocar, necessariamente, a adoção de política monetária restritiva. Isto se daria, pois, em função da boa reputação do governo, a inflação esperada pelos agentes convergiria para a meta anunciada pela AM (os agentes confiariam que a AM não trapacearia, ou seja, incorporariam sobre suas expectativas a credibilidade da política monetária), não havendo a necessidade de uma contração importante da oferta de moeda ${ }^{22}$. Neste caso, em que a AM possui credibilidade e não blefa, pode não haver trade-off entre inflação e desemprego (segundo quadrante do Quadro 1). Este argumento é válido também para o período anterior à adoção do regime de MI, desde que a AM tenha credibilidade.

Em suma, segundo a corrente mainstream, não se espera uma correlação negativa entre os valores contemporâneos da inflação e do investimento, quer antes da adoção do regime de metas, quer no período posterior à sua adoção. Neste caso, espera-se que o coeficiente $\alpha_{7}$ seja nulo ou positivo.

\section{Estimação do modelo de investimento e resultados}

Visando testar as hipóteses derivadas da ortodoxia e da heterodoxia econômicas a respeito da relação entre inflação corrente e investimento corrente no âmbito do regime de MI, a equação (6) será estimada para 17 países.

Metodologia e dados utilizados - Serão agrupados dados de variáveis macroeconômicas dos países que adotam o sistema de MI e os coeficientes do modelo (equação 6) serão estimados através do método de dados de painel. Os 17 países que adotam o regime de MI considerados na estimação são: África do Sul, Austrália, Brasil, Canadá, Chile, Coreia do Sul, Espanha, Finlândia, Hungria, Israel, México, Nova Zelândia, Peru, Polônia, Reino Unido, Suécia e Tailândia. O período de análise é de 1980 a 2005. Os dados têm periodicidade anual. A Formação Bruta de Capital Fixo (FBKF) foi utilizada como proxy para o investimento agregado. Os dados que compõem as séries da FBKF, do produto, do crédito doméstico e da taxa de juros correspondem aos valores reais dessas variáveis (equação 6). Utili-

\footnotetext{
${ }^{22}$ Este argumento é conhecido na literatura como "A Crítica de Lucas".
} 
zou-se como deflator para o cálculo dessas variáveis os dados sobre inflação que constam do banco de dados do Fundo Monetário Internacional (FMI). Os dados utilizados foram todos extraídos do FMI (planilhas de dados financeiros IFS).

Inicialmente, estimou-se o modelo pelos métodos de efeitos fixos (OLS) e de efeitos aleatórios (GLS) visando realizar testes para a escolha de um modelo de efeitos fixos ou de efeitos aleatórios (testes de Hausman e de Breusch-Pagan). Além disso, essas estimações possibilitam a execução dos testes de heterocedasticidade e de correlação serial. Os resultados das respectivas estimações estão nas Tabelas 1 e 2.

Tabela 1: Estimação OLS de efeitos fixos

\begin{tabular}{l|c|c|c|c}
\hline $\begin{array}{l}\mathrm{R}^{2}=0,4239 \\
\text { Corr }\left(\mathrm{u}_{\mathrm{i}}, \mathrm{Xb}\right)=-0,1687 \\
\text { Intervalo de Confiança }=95 \%\end{array}$ & $\begin{array}{r}\text { no. observações }=425 \\
\text { no. de painéis }=17\end{array}$ \\
\hline FBKF & Coeficiente & Erro-padrão & Estatística $\mathrm{t}$ & $\mathrm{P}>$ [t] \\
\hline VGDP & 1,102365 & 0,204835 & 5,38 & 0,000 \\
CRED & 0,331848 & 0,021610 & 15,36 & 0,000 \\
TJR & $-0,001393$ & 0,007045 & $-0,20$ & 0,834 \\
VIP & $-0,423660$ & 0,346430 & $-1,22$ & 0,222 \\
DPWIP & 0,706475 & 0,552467 & 1,28 & 0,202 \\
CONST & 56,701930 & 2,693300 & 21,05 & 0,000 \\
\hline
\end{tabular}

Fonte: Elaboração própria. A letra $\vee=\Delta=$ variação.

Tabela 2: Estimação GLS de efeitos aleatórios

\begin{tabular}{|c|c|c|c|c|}
\hline \multicolumn{3}{|c|}{$\begin{array}{l}\mathrm{R}^{2}=0,4237 \\
\text { Corr }\left(\mathrm{u}_{\mathrm{i}}, \mathrm{Xb}\right)=0 \text { (assumido) } \\
\text { Intervalo de Confiança }=95 \%\end{array}$} & \multicolumn{2}{|c|}{$\begin{array}{r}\text { no. observações }=425 \\
\text { no. de painéis }=17 \\
\text { distribuição ui } \sim \text { gaussiana }\end{array}$} \\
\hline FBKF & Coeficiente & Erro-padrão & Estatística t & $P>[t]$ \\
\hline VGDP & 1,0536270 & 0,2036480 & 5,17 & 0,000 \\
\hline CRED & 0,3272807 & 0,0214433 & 15,26 & 0,000 \\
\hline TJR & $-0,0018607$ & 0,0070415 & $-0,26$ & 0,792 \\
\hline VIP & $-0,3964438$ & 0,3450770 & $-1,15$ & 0,251 \\
\hline DPWIP & 0,5219423 & 0,5439720 & 0,96 & 0,337 \\
\hline CONST & 57,0052200 & 4,0914430 & 13,93 & 0,000 \\
\hline
\end{tabular}

Fonte: Elaboração Própria.

No teste de Breusch-Pagan o valor da estatística do multiplicador de Lagrange (LM) encontrado foi $L M=398,01$. A estatística LM segue uma distribuição $\chi^{2}$ com 1 g.l. Assim, como $\chi^{2}(1)$ crítico é 3,5, rejeitamos a hipótese $\mathrm{H}_{0}$ em favor do modelo de efeitos aleatórios. Ademais, o teste de Hausman falhou por não conseguir encontrar condições assimptóticas (o valor de $\chi^{2}$ encontrado negativo). Portanto, assume-se a condição de não-correlação entre os efeitos não observados e as variáveis explicativas do modelo (efeitos aleatórios). Assim, aplica-se o método dos mínimos quadrados generalizados para estimar o modelo.

Quanto aos testes de heterocedasticidade e de autocorrelação, rejeitou-se a 
hipótese de homocedasticidade entre os painéis, pois o coeficiente de Wald foi $\chi^{2}$ $(17)=8191,83$, que é maior do que o $\chi^{2}(17)$ crítico. Conforme o teste de autocorrelação entre painéis de Wooldridge, a estatística de teste $\mathrm{F}(1,16)=165$,311 é maior do que a estatística de teste $\mathrm{F}(1,16)$ crítica, ou seja, pode-se negar a hipótese Ho em favor da autocorrelação de $1^{a}$. ordem entre os resíduos. Em função destes resultados, o modelo foi estimado utilizando-se o método dos mínimos quadrados generalizados com correção para heterocedasticidade e para autocorrelação, conhecido na literatura por FGLS (Feasible Generalized Least Square). Os resultados estão na Tabela 3.

Tabela 3: Estimação do modelo — FGLS

Painel heterocedástico e com autocorrelação de $1^{\text {a }}$ ordem $(A R(1))$

$A R(1)$ com coeficiente de autocorrelação comum entre os painéis

Painel balanceado

Correção de resíduos: método Durbin-Watson

$\mathrm{n}^{\circ}$ de observações $=425$

Intervalo de Confiança = 95\%

$\mathrm{n}$ 을 de painéis $=17$

\begin{tabular}{c|c|c|c|c}
\hline FBKF & Coeficiente & Erro-padrão & Estatística $z$ & $P>[z]$ \\
\hline VGDP & 0,5674731 & 0,0494345 & 11,48 & 0,000 \\
CRED & 0,1459094 & 0,0085315 & 17,10 & 0,000 \\
TJR & $-0,0047610$ & 0,0011721 & $-4,06$ & 0,000 \\
VIP & 0,4739688 & 0,0972607 & 4,87 & 0,000 \\
DPWIP & $-0,5860688$ & 0,1503114 & $-3,90$ & 0,000 \\
CONST & 72,6917100 & 2,742428 & 26,51 & 0,000 \\
\hline
\end{tabular}

Fonte: Elaboração própria

Todos os parâmetros estimados do modelo foram estatisticamente significativos ao nível de $1 \%$. O coeficiente estimado da variação do produto (VGDP) foi positivo $\left(\alpha_{2}=0,567431\right)$, indicando que o modelo acelerador pode explicar o investimento. O coeficiente estimado da variável crédito bancário (CRED) também foi positivo $\left(\alpha_{3}=0,1459\right)$, indicando que o aumento do crédito bancário aumenta o investimento agregado da economia. Com relação à taxa de juros real (TRJ), o coeficiente estimado foi negativo. Entretanto, o valor absoluto do coeficiente foi muito pequeno.

Os resultados dos coeficientes estimados da inflação (VIP) e da dummy piece wise (DPWIP) mostram que, após adoção do regime de MI, um aumento do índice de preços torna a FBKF menor, ou seja, há uma correlação negativa e contemporânea entre a variação do índice de preços e o investimento, confirmando o resultado esperado pela abordagem pós-keynesiana. O coeficiente estimado da variação do índice de preços (VIP) foi positivo $\left(\alpha_{5}=0,4739688\right)$ e o coeficiente da DPWIP foi negativo $\left(\alpha_{6}=-0,5860688\right)$, ambos significativos ao nível de significância de $1 \%$.

Conforme a abordagem pós-keynesiana, antes da adoção do regime de MI o coeficiente da inflação (VIP) não seria, necessariamente, negativo (coeficiente $\alpha_{5}$ ). 
O coeficiente estimado $\alpha_{5}=+0,4739688$, portanto, é um resultado esperado tanto na perspectiva do mainstream, como também na visão pós-keynesiana.

De outro lado, o valor do coeficiente estimado da dummy piece wise foi negativo $(-0,5860688)$. O fato de o coeficiente estimado da dummy piece wise ser estatisticamente significativo, independentemente do sinal, confirma a hipótese de quebra estrutural deste coeficiente após a adoção do regime de MI. Ou seja, houve uma mudança dos efeitos da inflação sobre o investimento no período posterior à implementação deste regime de metas. Ademais, tal coeficiente é negativo e, em módulo, maior que o coeficiente estimado da inflação (VIP). O valor do coeficiente estimado de VIP, após a adoção do regime de MI, foi $\alpha_{7}=\alpha_{5}+\alpha_{6}=-0,1121$. Este resultado corrobora com a hipótese de que, após a adoção do regime de MI, quanto maior for o aumento dos preços no presente, maiores serão as expectativas correntes de adoção (futura) de política monetária contracionista, o que deprime a emc, desestimulando o investimento corrente.

\section{CONSIDERAÇÕES FINAIS}

Na economia monetária a moeda não é neutra, quer no curto prazo, quer no longo prazo. A esfera financeira interage com a esfera real, determinando o produto, o emprego e os preços. Nesta economia prevalece o circuito Finance-Investimento-Poupança-Funding, em que expectativas não ergódicas quanto ao retorno esperado do investimento têm papel crucial para a determinação deste. Ademais, expectativas quanto à política monetária podem induzir mudanças na preferência pela liquidez dos agentes, afetando a demanda efetiva e a emc e, portanto, o investimento.

Não há, em princípio, correlação positiva entre inflação e formação (pelos agentes econômicos) de expectativas de política monetária contracionista. Sendo a moeda não-neutra, a contração da oferta de moeda ensejada pela AM afeta os preços, e, também, o produto e a acumulação de capital. Neste caso, a AM pode não ter como prioridade o combate à inflação, ou, ainda, esta pode ser controlada por meio de outras políticas distintas da política monetária.

Todavia, se ocorre a adoção do regime de MI, o compromisso rigoroso da AM com a convergência da inflação em relação à meta estipulada é assumido e explicitado para os agentes econômicos. Neste caso, postulou-se que quanto maior for a inflação observada, maiores deverão ser as expectativas correntes de adoção de política monetária contracionista. Estas expectativas, por seu turno, implicam queda da emc e desestímulo ao investimento corrente.

Deste modo, foi estimada uma equação de investimento que incorpora entre as variáveis explicativas as expectativas de política monetária. A proxy utilizada para tais expectativas foi o diferencial de preços e uma variável dummy piece wise para o diferencial de preços foi contemplada entre os termos explicativos da equa- 
ção. Esta equação foi estimada para 17 países (1980-2005) pelo método de Dados de Painel. Baseando-se na abordagem pós-keynesiana, postulou-se que após a adoção do regime de MI nesses países teria ocorrido uma quebra estrutural no parâmetro do diferencial de preços, que seria negativo após a implementação do regime de metas. Esse sinal negativo se daria visto que após a adoção do regime de metas deve haver uma correlação positiva entre inflação corrente e expectativas correntes de política monetária restritiva. Isto produz uma correlação negativa entre inflação corrente e investimento corrente.

De outro lado, usando o conceito de neutralidade da moeda como linha divisória entre heterodoxia e ortodoxia econômicas, na visão ortodoxa a moeda é neutra (pelo menos) no longo prazo. Neste caso, o combate à inflação não deve afetar o lado real da economia, isto é, não afetaria a acumulação de capital, no longo prazo. Ademais, sugeriu-se que, seja baseando-se em Lucas (1981), ou em Barro e Gordon (1994), não há por que esperar uma correlação negativa entre valores contemporâneos da inflação e do investimento. Lucas (1981) argumenta que há uma correlação positiva entre preços e investimento, enquanto Barro e Gordon (1994) sugerem que um governo com má reputação deve aplicar política monetária restritiva, buscando a convergência da inflação com a meta estipulada e, também, a restauração de sua credibilidade. Todavia, neste caso, se houver uma correlação negativa entre inflação e investimento no curto prazo, esta não seria entre os valores contemporâneos dessas variáveis.

Os resultados da estimação da equação supracitada sugerem a validade da hipótese de mudança não apenas do coeficiente da inflação como também do sinal deste coeficiente, após a implementação do regime de MI nos países estudados. O coeficiente estimado da dummy piece wise apresentou sinal negativo. Este resultado é uma evidência em favor da hipótese de cunho pós-keynesiano. Segundo esta hipótese, sendo a moeda não-neutra, quanto maior for a inflação observada no âmbito do regime de MI, maiores serão as expectativas correntes de política monetária contracionista, com efeitos deletérios sobre a emc e sobre o investimento corrente.

\section{REFERÊNCIAS BIBLIOGRÁFICAS}

AMADO, A.M. (2000) Limites monetários ao crescimento: Keynes e a não neutralidade da moeda. Porto Alegre, Ensaios FEE, ano 21, n. 1.

BANCO CENTRAL DO BRASIL (1999) Relatório de Inflação, v.1, n.1, p. 89, junho. <http.www.bcb. gov.br/?REINFL.

BARRO, R.J. \& GORDON, D.B. Rules, discretion, and reputation in a model of monetary policy. In PERSSON, T. \& TABELliNI, G. (Orgs.) (1994) Monetary and fiscal policy, Volume 1: credibility. Massachusetts, MIT Press.

BERNANKE S.B.; LAUBACH, T.; MISHKIN, F.S.; POSEN, A.S. (1999) Inflation targeting: lessons from the international experience. Princeton University Press.

CARVALHO, F.J.C. (1992a) Mr Keynes and the post Keynesians: principles of macroeconomics for a monetary production economy. Edward Elgar. 
CARVALHO, F.J.C. (1992b) Moeda, produção e acumulação: uma perspectiva Pós Keynesiana. In SILVA, M.L.F. (org) Moedas e produção: teoria comparadas. Brasília, ed. UnB.

CARVALHO, F.J.C. (1993) Sobre a endogenia da oferta de moeda: réplica ao professor Nogueira da Costa. Revista de Economia Política, vol 13, n. 3 (51), julho-setembro.

CARVALHO, F.J.C. (1999) Políticas Econômicas para Economias Monetárias. In Lima, G.T., Sicsú, J. \& Paula, L.F. Macroeconomia Moderna: Keynes e a Economias Contemporânea. Rio de Janeiro, Ed. Campus.

CARVALHO, F.J.C.; SOUZA, F.E.P.; SICSÚ, J.; PAULA, L.F.R. \& STUDART, R. (2001) economia monetária e financeira: Teoria e Política. Rio de Janeiro, Ed. Campus.

CHICK, V. (1993) Macroeconomia após Keynes: um reexame da Teoria Geral. Rio de Janeiro, Forense Universitária.

DAVIDSON, P. (1992) International money and the real world. London, Macmillan, secund edition.

DAVIDSON. P. (1999) Colocando as evidências em ordem: macroeconomia de Keynes versus velho e novo-keynesianismo. In Macroeconomia Moderna: Keynes e a economia contemporânea. Rio de Janeiro, Ed Campus, cap 1.

FERREIRA, A.B. (2004) Metas para a inflação e vulnerabilidade externa: um estudo do Brasil. 2004. 150f. Belo Horizonte, Tese (Mestrado em Economia) - Cedeplar-UFMG.

FRIEDMAN, M. (1968) The Role of Monetary Policy. American Economic Review, vol. 58, março, pg. 1-17.

GREENE, JOSHUA e VILLANUEVA, DELANO (1991) La Inversion Privada en los Países en Desarrolo: Un Análisis Empírico. Fondo Monetário Internacional (FMI). IMF Staff Papers, vol.38, no.1. Marzo.

KEYNES, J.M. (1988a) A teoria geral do emprego, do juro e da moeda. São Paulo, Nova Cultural. KEYNES, J.M. (1988b) Teorias alternativas da taxa de juros. In Clássicos da Literatura Econômica, Rio de Janeiro, IPEA/INES

KEYNES, J.M. (1988c) A teoria ex ante da taxa de juros. In Clássicos da Literatura Econômica, Rio de Janeiro, IPEA/INPES.

LUCAS, R.E.Jr. (1972) Expectations and the neutrality of money. Journal of economic theory 4, 103124.

LUCAS, R.E.Jr. (1973) Some International Evidence on Output-Inflation Tradeoffs. The American Economic Review, 63 (3), 326-334.

LUCAS, R.E.Jr. (1981) Understanding business cycles. In LUCAS, R.E.Jr., Studies in business cycle, Massachusetts, MIT Press.

MISHKIN, F.S; Inflation Target. (2001) In A Encyclopedia of Macroeconomics. Brian Vane and Howard Vine.

MISHKIN, F.S. 2004. “Can Inflation Targeting Work in Emerging Market Countries?”. National Bureau of Economic Research. Working Paper 10646. Cambridge.2004.

MINSKY, H.P. (2986) Stabilizing and unstable economy. New Haven, Yale University Press.

MOLLO, M.L. (2004) Ortodoxia e heterodoxia monetárias: a questão da neutralidade da moeda. Revista de Economia Política, v.24, n. 3(95), julho-setembro.

PAULA, L.F. (1999) Teoria da firma bancária. In Lima,G.T.; Sicsú,J. \& De Paula,L.F.R. Macroeconomia Moderna: Keynes e a economia contemporânea. Rio de Janeiro, Ed. Campus.

PINDYCK, R. S. e RUBINFELD, D. L. (2004) Economia - Modelo e Previsões. Tradução da 4ª Edição. Ed. Campus.

RESENDE, M.F.C. e LIMA, F. (2007) Metas de Inflação e Investimento: O Caso do Brasil. São Paulo, Revista da Sociedade Brasileira de Economia Política, n. 21, Dezembro.

SACHS, J.D. \& LARRAIN, F.B. (1995) Macroeconomia. São Paulo, Makron Books.

SICSÚ, J. (2007) Emprego, Juros e Câmbio: finanças globais e desemprego. Rio de Janeiro, Elsevier.

STUDART, R. (1995) Investment Finance in Economic Development, London, Routledge.

SVENSSON, L.O. (1998) "Inflation Targeting as a Monetary Policy Rule”. NBER. 


\section{APÊNDICE}

Um teste empírico da hipótese de trade-off entre produto e inflação está em Lucas (1973). As soluções do modelo de equilíbrio de oferta-demanda de Lucas (1973) correspondem às equações abaixo, onde $\mathrm{x}=$ demanda agregada; $y_{c t}=$ componente cíclica que varia com os preços relativos percebidos pelos produtores e com seu valor defasado; $\delta=$ taxa do produto natural; $\pi$, $\gamma$ e $\beta$ são os parâmetros a serem estimados.

$$
\begin{aligned}
& y_{c t}=-\pi \delta+\pi \Delta x_{t}+\lambda y_{c, t-1} \\
& \Delta P_{t}=-\beta+(1-\pi) \Delta x_{t}+\pi \Delta x_{t-1}-\lambda \Delta y_{c, t-1}
\end{aligned}
$$

As equações (1) e (2) são os valores de equilíbrio da taxa de inflação e do produto real (como desvios porcentuais da tendência), estimadas em Lucas (1973) para 18 países no período 1952-1967 através do método de Mínimos Quadrados Ordinários (MQO). Os dados, obtidos no Yearbook of National Accounts Statistics, são trimestrais.

Os resultados das estimações indicam que "em um país com preços estáveis, como os EUA, políticas que aumentam a renda nominal tendem a ter um efeito inicial grande sobre o produto real, junto com positivo e pequeno efeito inicial sobre a taxa de inflação" (Lucas, 1973, p. 332). Ou seja, a taxa de inflação e o produto - e, por conseguinte, o investimento (Lucas, 1981, pp.230-231) - variam na mesma direção. Lucas (1973, p. 333) atribui esse resultado à confusão dos agentes entre mudanças do nível geral de preços e mudanças de preços relativos. Estes resultados de Lucas devem ser vistos com cautela. A metodologia empregada (MQO) não considera a possibilidade de "correlação espúria" entre variáveis. Visto se tratar de séries temporais, algum método de análise de cointegração deveria ter sido adotado 